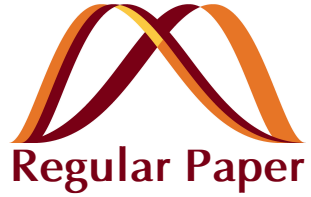

\section{Design and Evaluation of a Piezoelectric Energy Harvester Produced with a Finite Element Method}

\author{
Chul Min Kim, Chang-Il Kim, Joo-Hee Lee, Jong-Hoo Paik, Jeong-Ho Cho, \\ Myoung-Pyo Chun, Young-Hun Jeong, and Young-Jin Lee ${ }^{+}$ \\ Korea Institute of Ceramic Engineering and Technology, Seoul 153-801, Korea
}

Received June 22, 2010; Revised August 9, 2010; Accepted September 1, 2010

\begin{abstract}
Piezoelectric energy harvesting uses piezoelectric, which is able to convert unused mechanical vibration energy to electrical energy, such as with motor and machinery. The piezoelectric energy harvester was constructed with a cantilever made of lead zirconate titanate with a metal plate. The primary material was soft lead zirconium titanate (PZT-5H) due to the large strain availability, acceptable mechanical strength and high piezoelectric constant. This technique's drawback is that the energy efficiency is lower than the other energy harvesting methods, but this study increases the output electric power efficiency by analyzing a finite element method for the structure of the piezoelectric energy harvester. We manufactured two cantilever types as follows: the L-60 and L-33 bimorph piezoelectric energy harvesters. Their resulting energy harvesters were able to obtain high voltage values as follows: $27.4 \mathrm{mV}$ and $40.6 \mathrm{mV}$. Moreover, these results have a similar band of resonance frequency it comparison to the simulation. Consequently, this study was confirmed with validity. The output electric powers of the L-60 and L-33 types have $3.1 \mathrm{~mW} / \mathrm{s}$ and $5.8 \mathrm{~mW} / \mathrm{s}$ with $47 \mathrm{~Hz}$ and $148 \mathrm{~Hz}$ of resonance frequency and then, the load resistivities were $100 \mathrm{k} \Omega$ and $10 \mathrm{k} \Omega$, respectively.
\end{abstract}

Keywords: Piezoelectric energy harvester, PZT, Finite element method, Resonance frequency, Bimorph

\section{INTRODUCTION}

Energy harvesting, defined as a process in which energy is derived from external sources such as solar power, thermal energy, wind energy and kinetic energy captured, has been widely investigated [1-5]. Table 1 shows the comparison of power density generated from various power sources. Although solar energy has a relatively large power density $\left(15 \mathrm{~mW} / \mathrm{cm}^{3}\right)$ outside, it sharply decreases inside [6]. Moreover, energy produced via solar power is negligent when it is dark outside. However, since vibration is less dependent on the place and time, it is more valuable for energy harvesting.

Piezoelectric energy harvesting is well known to convert mechanical energy, such as vibration, to electrical energy. The technique has some advantages when compared to other energy harvesting techniques. Primarily, it has a very simple structure,

\footnotetext{
${ }^{\dagger}$ Author to whom all correspondence should be addressed: E-mail: yjlee@kicet.re.kr
}

composed of piezoelectric ceramics and conducting electrodes. Moreover, it is always functional within the operation frequency ranges whenever ambient vibration exists [7].

Piezoelectric energy harvesting has attracted much interest for use in various portable electronic devices due to some strong advantages. In particular, its low-power consumption could make the weight of batteries abruptly decrease and self-powered devices more available in the ubiquitous life of harvesting mechanical energy [8-10].

However, the technology of piezoelectric energy harvesting is only able to produce a few microwatts, which results from a high voltage, but a ultimately low current, when compared to other harvesting technologies of solar or wind energy. Thus, recent topics of piezoelectric energy harvesting lie in the enhancement of piezoelectric constants for a higher power density and structure development of energy harvesters within an optimized scheme. In order to improve the piezoelectric properties, we have optimized a structure of piezoelectric energy harvesters as a bimorph type cantilever by a finite element method. Further- 
Table 1. Comparison of the power density generated from various power sources.

\begin{tabular}{lll}
\hline Power source & Power density & Source of information \\
\hline \hline $\begin{array}{l}\text { Solar } \\
\text { (outdoors at noon) }\end{array}$ & $15 \mathrm{~mW} / \mathrm{cm}^{3}$ & Commonly available \\
$\begin{array}{l}\text { Solar } \\
\text { (outdoors at noon) }\end{array}$ & $15 \mu \mathrm{W} / \mathrm{cm}^{3}$ & Commonly available \\
Vibrations & $116 \mu \mathrm{W} / \mathrm{cm}^{3}$ & \\
Temperature gradient & $40 \mu \mathrm{W} / \mathrm{cm}^{3}$ from $10^{\circ} \mathrm{C}$ & Roundy [2] \\
Acoustic noise $(100 \mathrm{~dB})$ & $960 \mathrm{nW} / \mathrm{cm}^{3}$ & Commolife \\
\hline
\end{tabular}

more, we have fabricated a piezoelectric energy harvester using piezoelectric materials with excellent piezoelectric properties and then have evaluated it systematically.

\section{EXPERIMENTS}

\subsection{Piezoelectric energy harvesting}

Piezoelectric energy harvesting, which converts mechanical vibration energy to electrical energy, generally uses a piezoelectric ceramic. The piezoelectric materials are normally classified as two different types, based on the energy conversion direction. The first one is the actuator type, in which the piezoelectric element undergoes a dimension change with an electric field application. The electric energy is converted into mechanical energy based on the indirect piezoelectric effect. The second type is called the sensor type, in which an electric charge is produced with the application of a mechanical vibration [11]. This study uses the sensor type and piezoelectric cantilever in order to harvest the surrounding waste energy. The output power density (W) is defined via the following Eq. (1):

$$
W=\frac{1}{2} \times g_{33} \times d_{33} \times F_{3}^{2} \times \frac{T}{w L}
$$

This equation consists of the force (F), thickness $(\mathrm{T})$, cantilever's length $(\mathrm{L})$, width $(\mathrm{W})$ piezoelectric constant $\left(\mathrm{d}_{33}\right)$, and output voltage coefficient $\left(\mathrm{g}_{33}\right)$. In order to produce a higher electrical harvest, the piezoelectric properties must be improved and the structure must be optimized [12].

\subsection{Design of the piezoelectric energy harvester using a finite element method}

Figure 1 shows the modeling of a piezoelectric energy harvester, which is fixed at line A. It consists of three layers with a top and bottom PZT layer and a metal shim middle layer, chosen for two reasons.

Firstly, the bending element has been chosen because the machinery demands lower resonance frequencies between 50 $\mathrm{Hz}$ and $150 \mathrm{~Hz}$, as well as the attainment of higher strains. Second, for a given force input, the cantilever results in the highest average strain, and the output power is closely related to the average strain developed in the bender. Therefore, in order to design an optimized structure, the variables were changed because the resonance frequency and output voltage were different due to cantilever variants, such as materials, length, and width. We used the metal plates aluminum $(\mathrm{Al})$, copper $(\mathrm{Cu})$, and steel use stainless (SUS). In order to check the varying PZT quality, the properties of PZT 4, PZT5A, PZT5H, and PZT 8 were used.

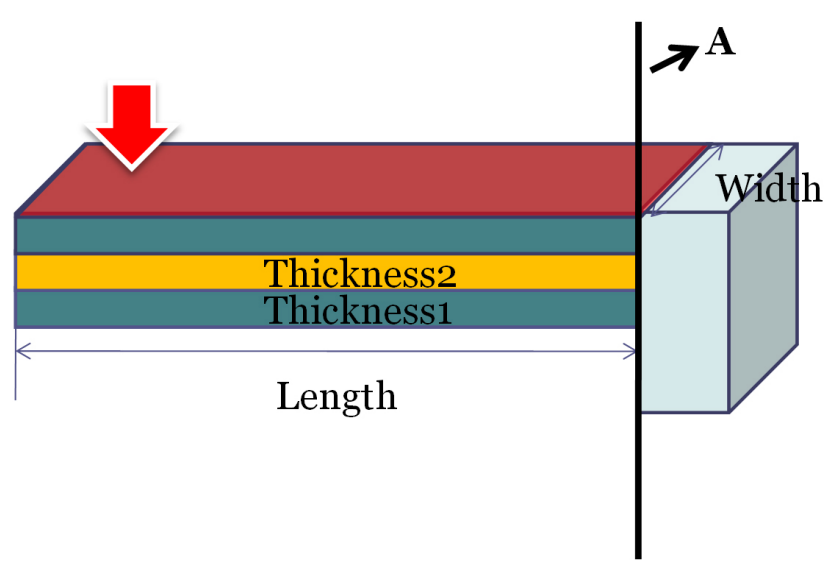

Fig. 1. The modeling of a two layer lead zirconium titanate (PZT) bender mounted as a cantilever beam.

Al: aluminum, SUS: steel use stainless, Cu: copper.

Table 2. Simulation variables.

\begin{tabular}{llll}
\hline \multicolumn{3}{c}{ Variables } \\
\hline Type & Length & Width & Materials \\
\hline \hline Bimorph & $30-90 \mathrm{~mm}$ & $2-45 \mathrm{~mm}$ & PZT5/Cu \\
\hline
\end{tabular}

PZT: lead zirconium titanate, Cu: copper.

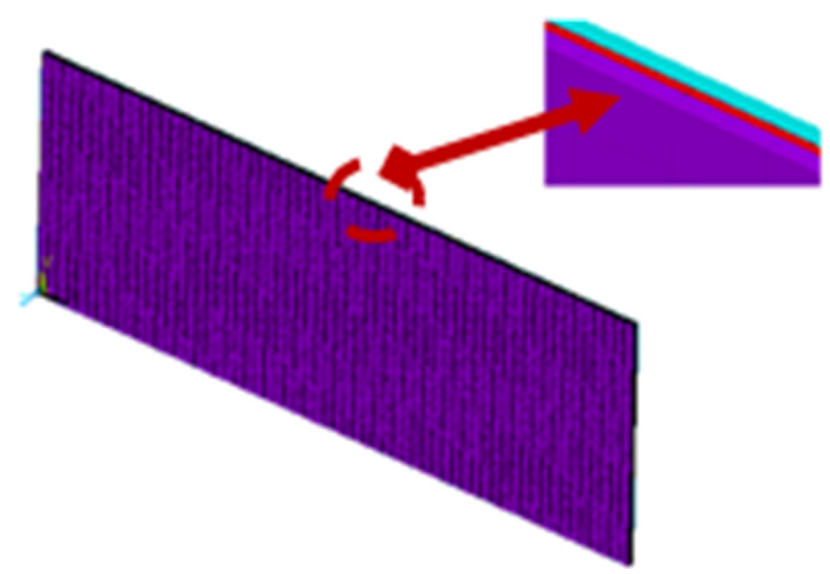

Fig. 2. The modeling using ANSYS simulation.

The simulation in ANSYS, ver. 10 (ANSYS Inc., Canonsburg, PA, USA)was used and modal, harmonic, and transients of the simulation analysis were performed. Figure 2 is the meshed cantilever and Table 2 shows the simulation condition variables. The damping coefficient is 0.1 and the electric fields are zero. The sine waveform's force is $1 \mathrm{~N}$, with a duration of 0.005 msec.

\section{RESULTS AND DISCUSSION}

3.1 Results for the resonance frequency and output voltage through a harmonic and transient analysis

\subsubsection{Tendency of the output voltage when changing the PZT and metal properties}

Transient analysis is able to attain an output voltage and was performed in order to select the PZT and metal materials [13]. 


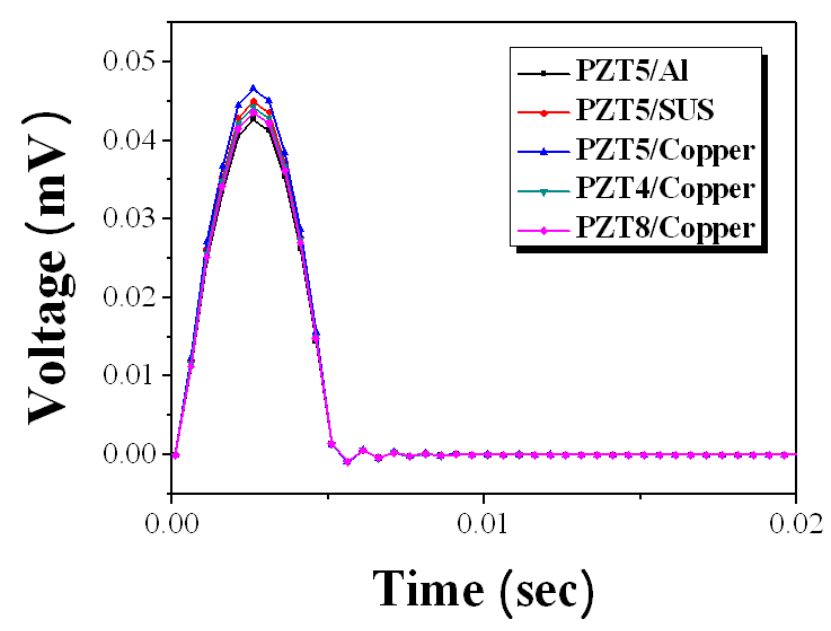

Fig. 3. Results of the output voltage when the materials are changed.

Table 3. Results of the output voltage $(\mathrm{mV})$ when the materials are changed.

\begin{tabular}{ll}
\hline Substrate & Output voltage $(\mathrm{mV})$ \\
\hline PZT5/Al & 0.045 \\
PZT5/SUS & 0.0427 \\
$\mathrm{PZT} 5 / \mathrm{Cu}$ & 0.0466 \\
$\mathrm{PZT} 4 / \mathrm{Cu}$ & 0.0443 \\
$\mathrm{PZT} / \mathrm{Cu}$ & 0.0436 \\
\hline
\end{tabular}

PZT: lead zirconium titanate, Al: aluminum, SUS: steel use stainless, Cu: copper.

The PZT material can be categorized into three types, as follows: soft, hard, and neutral. We simulated by selecting a PZT sheet and a metal plate. PZT is divided up into PZT4, PZT5H, and PZT8 [14]. These properties were reported within several papers and were known to simulate the piezoelectric energy harvester. The PZT5H is soft, and PZT 4 is hard, and PZT 8 has a neutral characteristic. Moreover, because the PZT sheet is patched to a metal plate, we also simulated the various types of metal plates, such as $\mathrm{Cu}, \mathrm{Al}$, and SUS. Figure 3 and Table 3 show the simulation output voltages for each material property. When the PZT properties were compared, PZT 4, PZT 5, and PZT 8 were $0.0443 \mathrm{~V}, 0.0466 \mathrm{~V}$, and $0.0436 \mathrm{~V}$, respectively. Copper has the highest output voltage of all the metals. Shown in the simulation results, the PZT 5H and the copper plate have a high output voltage in comparison to others. Therefore, the best materials are PZT5H and copper plate.

\subsubsection{Resonance frequency tendencies and the} output voltage when changing the length and width

Figures 4(a) and (b) show the resonance frequency and output voltage of the piezoelectric sheet while changing the length via harmonic and transient analysis. As the lengths are changed from $30 \mathrm{~mm}$ to $90 \mathrm{~mm}$, with a fixed width of $10 \mathrm{~mm}$, the output voltages decrease from $0.09 \mathrm{mV}$ to $0.03 \mathrm{mV}$ and the resonance frequency slopes also decrease. Therefore, a piezoelectric cantilever's width is one method used to improve the output voltage within industry.

Figures 5(a) and (b) show the resonance frequency and output voltage of the piezoelectric sheet when the width changes via harmonic and transient analysis. These widths are changed from $2 \mathrm{~mm}$ to $25 \mathrm{~mm}$, with a fixed length of $60 \mathrm{~mm}$. Its output voltage slope decreases when increasing from $2 \mathrm{~mm}$ until $15 \mathrm{~mm}$ of the width of the piezoelectric bimorph cantilever, but had close to the same values when the width if greater than $15 \mathrm{~mm}$. Contrary
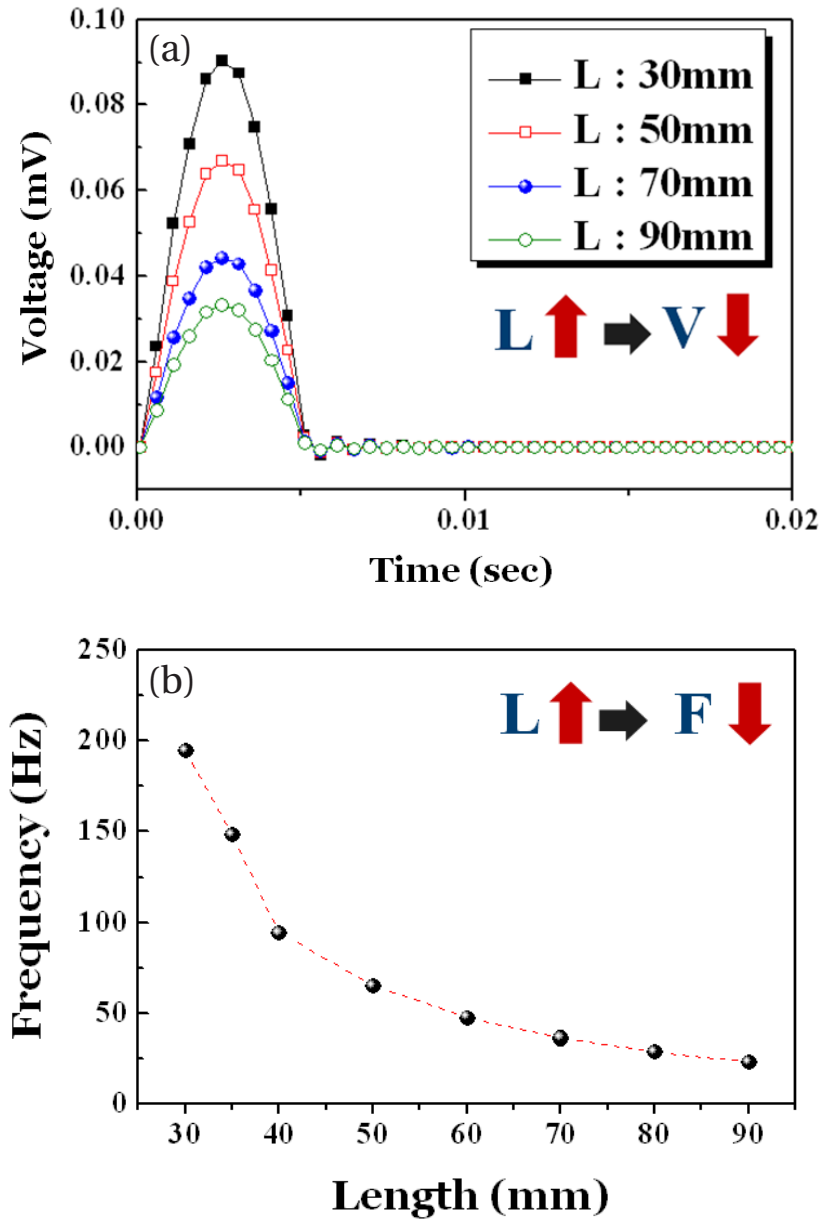

Fig. 4. Results of (a) output voltage $[\mathrm{mV}]$ and (b) Resonance Frequency $(\mathrm{Hz})$ when changing the cantilever length.

Table 4. Simulation results.

\begin{tabular}{lllll}
\hline Type & $\begin{array}{l}\text { Resonance } \\
\text { frequency } \\
(\mathrm{Hz})\end{array}$ & $\begin{array}{l}\text { Length } \\
(\mathrm{mm})\end{array}$ & $\begin{array}{l}\text { Width } \\
(\mathrm{mm})\end{array}$ & $\begin{array}{l}\text { Output } \\
\text { voltage } \\
(\mathrm{mV})\end{array}$ \\
\hline L-60 & 47 & 60 & 35 & 0.04 \\
L-33 & 148 & 33 & 35 & 0.09 \\
\hline
\end{tabular}

to the length results, the slope of the resonance frequency increases slightly. However, the length variable is more susceptible to resonance frequency because the width of the piezoelectric bimorph cantilever is almost unchanged when compared to the length. As mentioned, for the case of machinery, mechanical vibration has $50 \sim 150 \mathrm{~Hz}$, which is a natural frequency. In order to utilize this energy harvester, the lengths of $\geq 60 \mathrm{~mm}$ and $\leq 40 \mathrm{~mm}$ are not used because they have a resonance frequency of $\leq 50 \mathrm{~Hz}$ and $\geq 150 \mathrm{~Hz}$. Therefore, we selected the size of piezoelectric energy harvester via simulation results. The size is $60 \times 35 \times 0.02 \mathrm{~mm}^{3}$ and $33 \times 35 \times 0.02 \mathrm{~mm}^{3}$ and they have the resonance frequency of $50 \mathrm{~Hz}$ and $150 \mathrm{~Hz}$, respectively. Figures 4 and 5 and Table 4 show the simulation results for both the L-60 and L-33 piezoelectric energy harvester types.

\subsection{Evaluation of the power generation system}

\subsubsection{Measurement method}

In order to design a structure able to use $50 \mathrm{~Hz}$, Bimorph type 

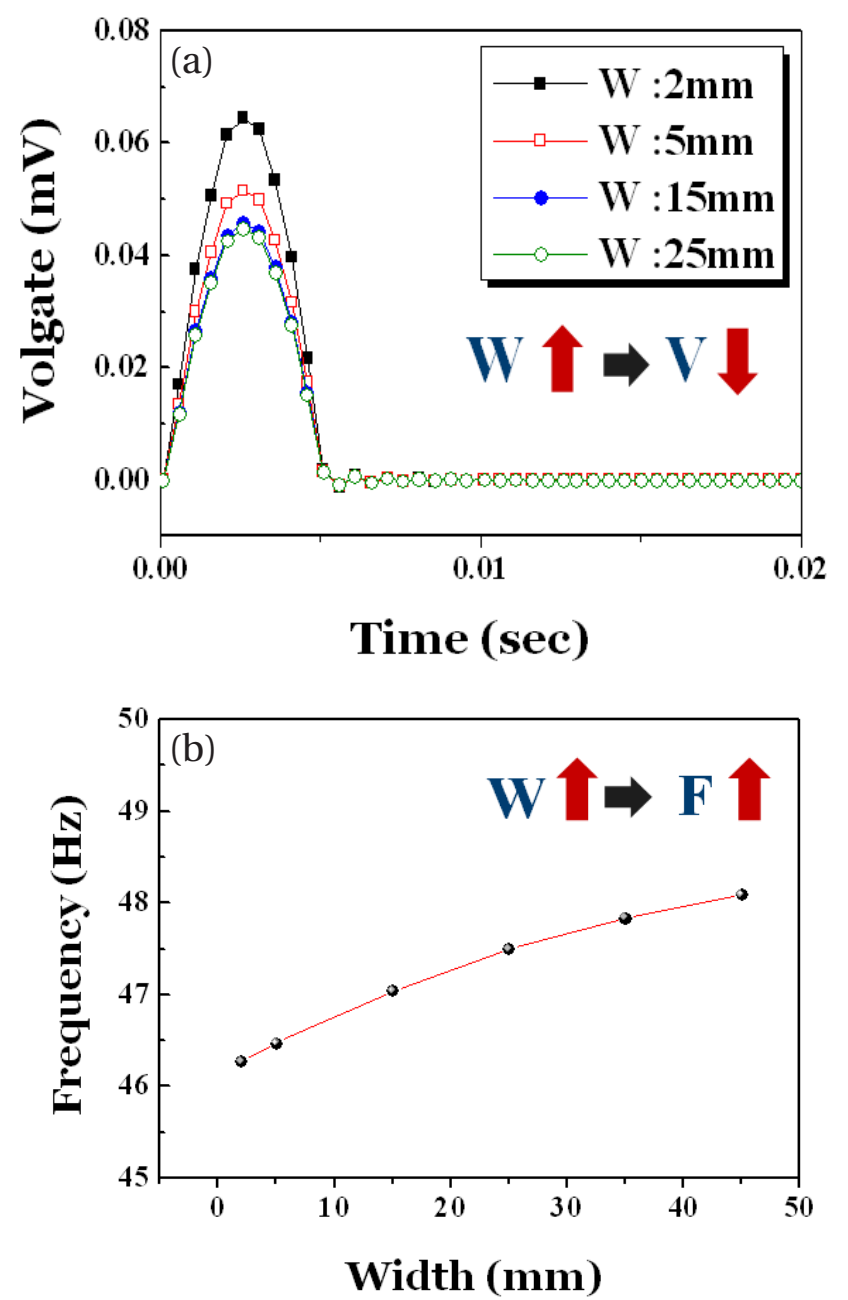

Fig. 5. Results of (a) output voltage (mV) and (b) resonance frequency $(\mathrm{Hz})$ when changing the cantilever width.

cantilevers are produced for demonstrating a feasibility study about the simulation results and measurement. Figures 6(a) and (b) show the produced bimorph piezoelectric energy harvester and then, we named one (a) sample L-60 and the other (b) sample L-33. The output voltages for each were measured with the first mode resonance frequency is the largest on the $\mathrm{Z}$ axis. Figure 7 shows the measuring instrument. When a vibration exciter was vibrated, the Piezoelectric Energy Harvester was measured with variable frequencies and load resistivities. Then, the output voltage was measured via an oscilloscope.

\subsubsection{Measurement and evaluation of L-60 and L-33 piezoelectric energy harvester types}

The measurement results in Fig. 8 show the output voltage $(\mathrm{mV})$ produced from both the L-60 and L-33 types when the input natural frequency changes. Then, the output voltage was measured when the frequency was $10 \sim 200 \mathrm{~Hz}$ and $10 \mathrm{M} \Omega$. In the resulting measurement, the output voltage obtained the best value within the resonance frequency band, but it dropped remarkably within the other bands. When the L-60 type has a resonance frequency of $47 \mathrm{~Hz}$, the output voltage was $27.4 \mathrm{mV}$. Similar to the L-33 type, it has $148 \mathrm{~Hz}$ and $40.6 \mathrm{mV}$. Moreover, these results have a similar band of resonance frequency in comparison to the simulation. Consequently, piezoelectric energy harvesters, having a resonance frequency of both $50 \mathrm{~Hz}$ and $150 \mathrm{~Hz}$, were
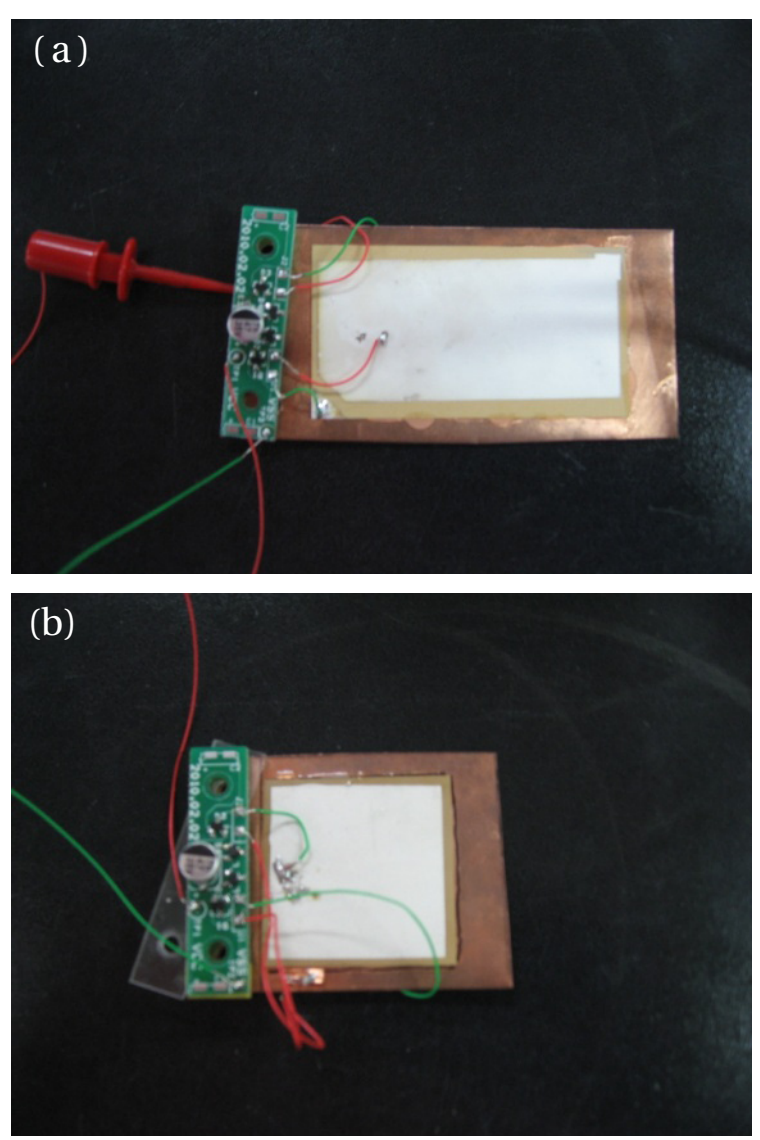

Fig. 6. The produced (a) L-60 and (b) L-33 bimorph piezoelectric energy harvester.

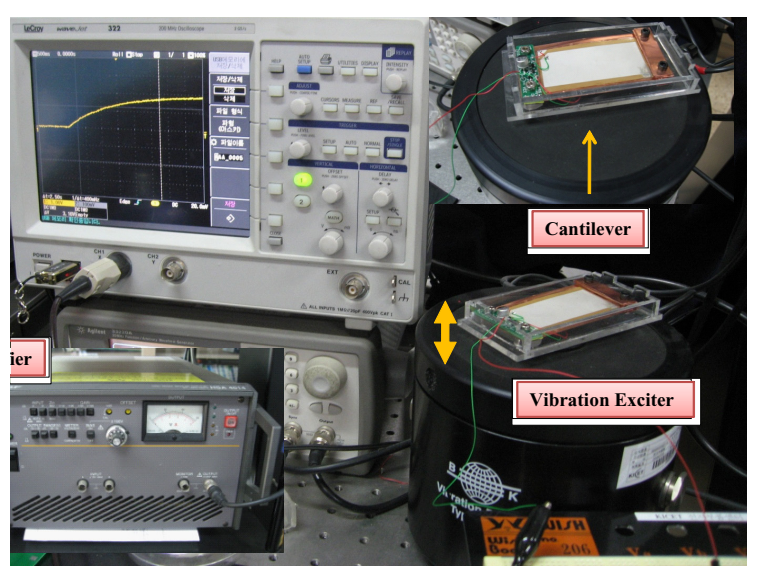

Fig. 7. Experimental setup.

produced.

Figures 9(a) and (b) show the measurement results of output power density for both L-60 and L-33 type energy harvesters at resonance frequency, which causes the load resistivity range to be from $1 \mathrm{k} \Omega$ to $10 \mathrm{M} \Omega$. As shown in Figure 9(a), the L-60 type was measured in order to prove the validity and the load resistivity was changed from $1 \mathrm{k} \Omega$ to $10 \mathrm{M} \Omega$ when the resonance frequency was $47 \mathrm{~Hz}$. The measurement results show that the best power can be attained at $3.1 \mathrm{mV}$ with a load resistivity of $100 \mathrm{k} \Omega$. Similar to the L-33 type, Fig. 9(b) shows the power density $(\mathrm{mV})$ when load resistivity was changed from $1 \mathrm{k} \Omega$ to $10 \mathrm{M} \Omega$ with a fixed frequency of $148 \mathrm{~Hz}$. 


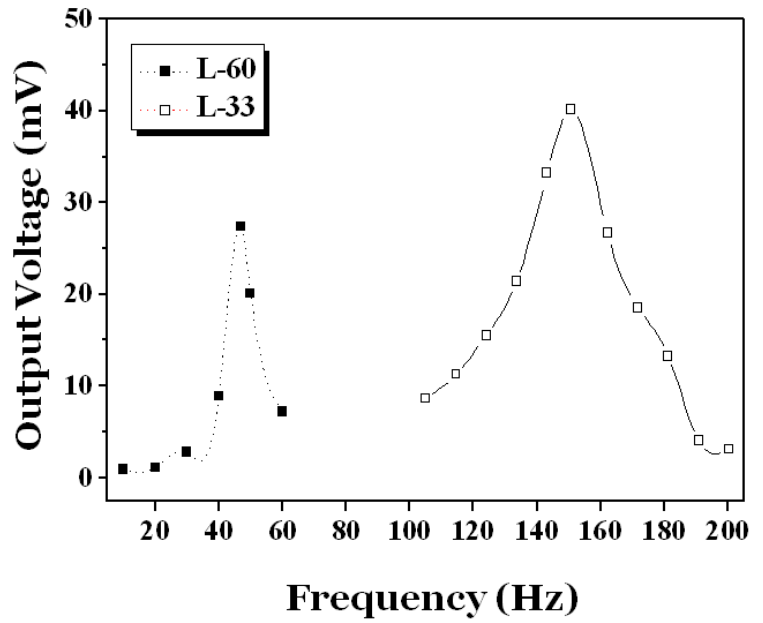

Fig. 8. Output voltages of L-60 and L-33 energy harvesters when changing the natural frequency input in the range of $10 \sim 200 \mathrm{~Hz}$.
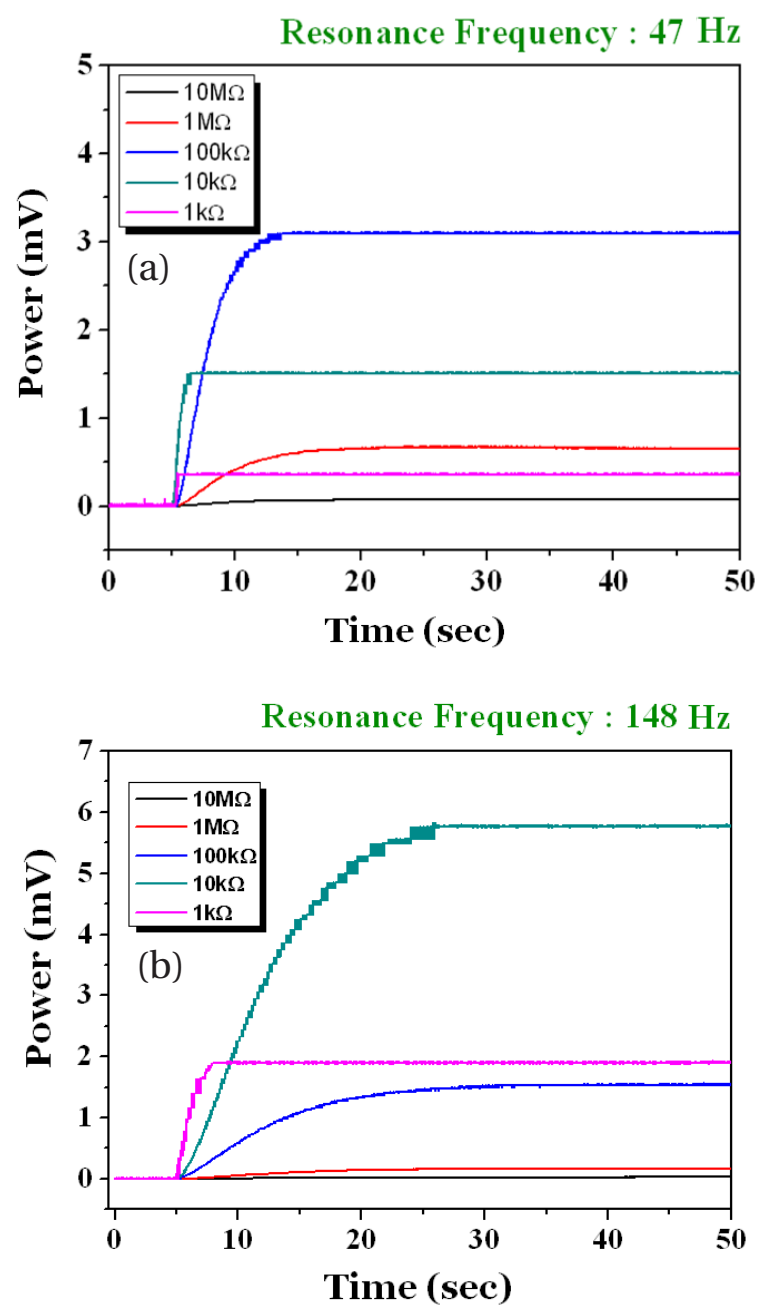

Fig. 9. Measured results for output power density of (a) L-60 type and (b) L-33 type when changing the load resistivity in the range of $1 \mathrm{k} \sim 10$ $\mathrm{M} \Omega$ at their resonance frequency.

This study uses a rectifier circuit in order to disregard the impedance matching and the capacitor of $47 \mu \mathrm{F}$. An analysis study for bimorph, the piezoelectric energy harvesters, having the

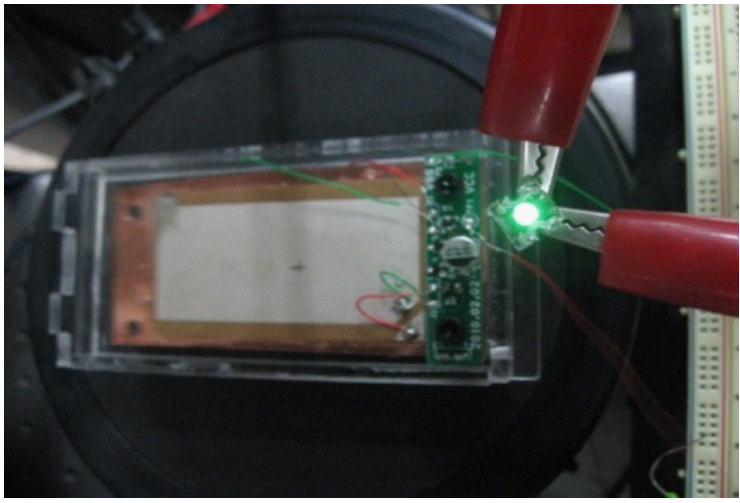

Fig. 10. Image of the illuminated LED.

resonance frequency of $50 \mathrm{~Hz}$ and $150 \mathrm{~Hz}$, were produced and the output voltages of L-60 and L-33 were then $3.1 \mathrm{~mW} / \mathrm{s}$ and $5.8 \mathrm{~mW} / \mathrm{s}$, respectively. Next, as shown in Figure 10, in order to check the output electricity, the produced piezoelectric energy harvester was connected to a Light Emitting Diode (LED) lamp (BIWV-PB5C3T, Ningbo-Bright cop., Ningbo, China). When the energy harvester vibrated, the LED lamp lit up.

\section{CONCLUSIONS}

In this study, the piezoelectric energy harvester is produced in order to use piezoelectric able to convert unused mechanical vibration energy to electrical energy, such as with motor and machinery, which has a natural frequency of approximately 50 150 Hz. Our primary focus was to investigate how to improve the energy efficiency.

First, in order to optimize the structure and show the tendency, a piezoelectric cantilever was designed and produced to demonstrate a feasibility study about the simulation results and measurements.

Second, the materials of the cantilever are selected and simulated with the resonance frequency and output voltage of the piezoelectric while changing the length and width via harmonic and transient analysis.

Third, shown in the simulation results, in order to design a structure able to use $50 \mathrm{~Hz}$ and $150 \mathrm{~Hz}$, Bimorph type cantilevers were produced and their sizes were $\mathrm{mm} 2$ and $\mathrm{mm} 2$. The output voltages of were measured where the first mode resonance frequency is the largest on the $\mathrm{Z}$ axis.

Finally, in the simulation results, we show that the LED lamp lit up when an energy harvester was vibrated. The power was compared between an L-60 and L-33 energy harvester, with output voltages of L-60 and L-33 being $3.1 \mathrm{~mW} / \mathrm{s}$ and $5.8 \mathrm{~mW} / \mathrm{s}$, respectively.

\section{ACKNOWLEDGMENTS}

This study was carried out with research funds provided by Korea Institute of Construction \& Transportation Technology Evaluation and Planning. The authors are grateful for the supports.

\section{REFERENCE}

[1] N. S. Shenck and J. A. Paradiso, IEEE Micro 21, 30 (2001) [DOI: 
$10.1109 / 40.928763]$.

[2] S. L. Eli and K. W. Paul, Smart Mater. Struct. 15, 1413 (2006) [DOI: 10.1088/0964-1726/15/5/030].

[3] E. Minazara, D. Vasic, F. Costa, and G. Poulin, Ultrasonics 44 Suppl 1, e699 (2006) [DOI: 10.1016/j.ultras.2006.05.141].

[4] M. Ericka, D. Vasic, F. Costa, and G. Poulain, IEEE Ultrasonics Symposium (Rotterdam, the Netherlands 2005 Sep. 18-21) p. 946 [DOI: 10.1109/ULTSYM.2005.1603007].

[5] H. A. Sodano, J. Lloyd, and D. J. Inman, Smart Mater. Struct. 15, 1211 (2006) [DOI: 10.1088/0964-1726/15/5/007].

[6] W. R. Heinzelman, A. Chandrakasan, and H. Balakrishnan, Proceedings of the 33rd Annual Hawaii International Conference on System Sciences (Maui, Hawaii 2000 Jun. 4-7) [DOI: 10.1109/ HICSS.2000.926982].

[7] C. B. Williams, R. C. Woods, and R. B. Yates, IEE Colloquium on Compact Power Sources (Digest No. 96/107) (London 1996 May 8) p. $7 / 1$.
[8] C. I. Kim, Y. H. Jeoung, Y. J. Lee, J. H. Paik, and S. Nahm, J. KIEEME 21, 1071 (2008).

[9] J. Baker, S. Roundy, and P. Wright, Energy Conversion Engineering Conference (San Francisco, CA 2005 Aug) p. 959.

[10] H. S. Yoon, G. Washington, and A. Danak, J. Intell. Mater. Syst. Struct. 16, 877 (2005) [DOI: 10.1177/1045389x05055759].

[11] T. J. Johnson, D. Charnegie, W. W. Clark, M. Buric, and G. Kusic, Proc. SPIE 6169, 61690D (2006) [DOI: 10.1117/12.659466].

[12] Q. M. Wang and L. Eric Cross, J. Am. Ceram. Soc. 82, 103 (1999) [DOI: 10.1111/j.1151-2916.1999.tb01729.x].

[13] C. M. Kim, Y. J. Lee, and J. H. Paik, J. KIEEME 22, 832 (2009).

[14] H. J. Lee and D. A. Saravanos, The Effect of Temperature Dependent Material Nonlinearities on the Response of Piezoelectric Composite Plates [NASA/TM 97-206216] (National Aeronautics and Space Administration Lewis Research Center, Cleveland, 1997). 